\title{
Management of an Inpatient Unit by Emergency Department Staff: An Exploration of Improvement in Patient Throughput
}

\author{
Denise C. Rhew ${ }^{1}$, PhD, RN, CNS, CEN, Ruth Anna H. Richards², BSN, RN, Jason Upham ${ }^{3}$, MSN, RN, CEN, Rachel \\ Keslar ${ }^{4}$, MSN, RN, CEN \\ ${ }^{l}$ Clinical Nurse Specialist, Emergency Services, Cone Health, Greensboro, NC, United States. \\ ${ }^{2}$ Emergency Nurse (Lead project owner), Cone Health, Greensboro, NC, United States. \\ ${ }^{3}$ Executive Director, Nursing Administration, Cone Health, Greensboro, NC, United States. \\ ${ }^{4}$ Clinical Nurse Educator, Emergency Services, Cone Health, Greensboro, NC, United States.
}

\author{
Article Details \\ Article Type: Research Article \\ Received date: $04^{\text {th }}$ November, 2019 \\ Accepted date: $26^{\text {th }}$ November, 2019 \\ Published date: $09^{\text {th }}$ December, 2019
}

"Corresponding Author: Denise C. Rhew, Department of Nursing, Clinical Nurse Specialist, Emergency Services, Cone Health, Greensboro, NC, United States. E-mail: Denise.Rhew@,conehealth.com

Citation: Rhew DC, Richard RAH, Upham J, Keslar R (2019) Management of an Inpatient Unit by Emergency Department Staff: An Exploration of Improvement in Patient Throughput. J Comp Nurs Res Care 4: 155. doi: https://doi.org/10.33790/ jenrc1100155.

Copyright: (C2019, This is an open-access article distributed under the terms of the Creative Commons Attribution License 4.0, which permits unrestricted use, distribution, and reproduction in any medium, provided the original author and source are credited.

\begin{abstract}
Background: Holding admitted patients in the Emergency Department (ED) influences the length of stay, discharges, and the quality of care provided regardless of who is responsible for that situation.

Purpose: To determine if transferring admitted patients holding in the ED to a dedicated inpatient nursing unit managed by ED staff would improve ED patient throughput and decrease Left Without Being Seen (LWBS).

Methodology: The ED department opened an inpatient nursing unit for patients waiting for an inpatient bed. Prior to the unit opening, staff shadowed on an inpatient unit to enhance their knowledge of the inpatient unit patient care flow. Select admitted patients holding for inpatient beds were transferred to this unit until an inpatient bed was assigned. Inpatient orders were initiated once patients arrived in the unit.
\end{abstract}

Results: Over nine months 11,115 patient care hours were transferred from the ED and helped with the bottle necking of patients in the ED. Patients who were transferred to the ED managed inpatient holding unit shared that they were so happy to get a private room with a bathroom, and that their families could stay with them while they waited for their inpatient bed assignment.

\section{Introduction}

It is commonly heard that some of main reasons the emergency department (ED) wait six to eight hours long because inpatient departments are short-staffed or do not expedite patient discharges. Instead of passing the consequences of long waits for inpatient beds onto patients and blaming staff for delays, ED leadership and staff decided to take ownership of the bottlenecking of patients waiting for medical inpatient beds in the ED. The ED opened a previously empty inpatient nursing unit and occupied it with their ED staff. Boarding patients in the ED has been shown to contribute to the increase in length of stay (LOS), mortality, leaving without being seen (LWBS), adverse events, and decreased patient and employee satisfaction [1 ].Boarding patients have been defined as patients that could be cared for outside of the ED in other areas of the hospital. The largest population of boarders in the ED are patients who have been admitted but must wait in the ED on an inpatient bed to become available or assigned [2]. This is problematic as the ED setting and staff are not equipped for or educated on implementing inpatient orders. The primary role of the ED is to quickly assess and triage patients for lifethreatening symptoms, stabilize them, and either discharge them after treatment or admit them to an inpatient department for further care.

In this ED, boarding inpatients' admission orders do not get initiated until the patient has been in the ED at least six hours due to the overcrowding in the ED and life-threatening priorities. Exceptions are any "Stat" or "Now" orders that are released from the admission orders and are initiated as quickly as possible. In addition, this ED like many others is faced with the challenge of improving patient throughput $[3,4]$. The aim of this pilot study was to identify whether placing select admitted patients holding in the ED in a dedicated inpatient holding unit ran by ED staff would improve patient through put and decrease patients leaving without being seen by an ED Provider.

\section{Background}

In November of 2018, an emergency department at an urban hospital in the southeastern United States decided to prepare for the forthcoming increase in patient volume that is usually seen around the winter months. At the same time, inpatient departments in the same facility were closing beds due to an inpatient nursing shortage and were not able to try other overflow options such as opening hall beds to take additional admitted patients. On any given day there could 15-20 patients holding in the ED waiting on an inpatient bed. Left without being seen rates were also rising due holding patients due to increase wait times from five to eight hours. To be proactive for the increased ED and inpatient volume during the winter months, the ED director decided to turn a closed inpatient nursing unit into a new holding unit for patients that are admitted to the hospital and are waiting for an inpatient bed assignment. The new 10-bed unit was broken up into two 5-bed nursing assignments. This unit is located on the 5 th floor in a central part of the hospital. The location was picked due to its accessibility to the ED, via elevators just outside the ED, and the location was close to the inpatient nursing departments, so that moving patients is easier once they are assigned to an inpatient 
bed. This unit was to be run by ED staff. An ED bedside nurse with two and a half years of nursing and emergency department experience was asked to be the point/lead nurse for this unit to ensure that the project ran smoothly.

\section{Methodology}

Emergency department leadership got approval to open their own inpatient holding unit to transfer admitted patients holding in the ED who were waiting to be assigned an inpatient bed. The ED director took over an unused inpatient nursing unit located on the central area of the 5th floor in the hospital. The director appointed one of the ED nurses to be the lead for this new unit. The nurse agreed to oversee the opening and running of the new holding unit and used this pilot project as her project to advance to the next level on the Clinical Ladder. Information about the new unit was communicated to the staff via shift huddles, staff meetings, and emails. ED team members could volunteer to work in the new inpatient holding unit. The staff was informed they would still be able to chart in the ED specific electronic healthcare record format they were accustomed to but would have to start inpatient admitting orders once the patient arrived in the holding unit. Staff was offered opportunities to shadow on inpatient nursing departments to prepare them for the flow of an inpatient nursing department. The staffs were asked to complete a inpatient RN shadowing survey (figure 1). The lead nurse developed a department checklist for the staff to make sure everyone knew what needed to be documented in the chart once the patient arrived in the department. The list included: release all signed and held orders, primary assessment, secondary assessment, update vital signs, skin assessment, hourly rounding, pain assessment, and send message to the pharmacy to verify medications, and order food if the patient has a diet order. Staffs were also asked to place a patient sticker on the checklist sheet and document the time the patient arrived in the unit, the time the patient left the unit, and the destination inpatient department. The ED charge nurse and holding unit lead nurse frequently assessed the ED boarders and holding unit criteria (Figure 2 ) to transfer medically stable admitted patients to the holding unit. The nurse-patient ratio was 1:5 for the 10-bed unit. The unit was staffed with two nurses and one tech when possible. They were able to open and close the holding unit as needed in response to patient volume. In addition, an ED nurse who had been placed on light duty was assigned to round on inpatient departments. His role was to help build relationships between the ED staff working on the holding unit and the inpatient staff. He also helped with opportunities identified to improve patient transitions to their admitted inpatient beds. Once the patient was assigned an inpatient bed, the handoff report was called to the receiving inpatient nurse and it was the responsibility of the receiving department to transport the patient.

\section{RN Shadowing on In-patient unit}

This is a great opportunity for us as ED nurses to see what the other side looks like. Please ask questions and learn as much as you can. Below are some questions to ask while shadowing on the unit.

Questions to ask while on the unit

- How do you time manage?

- What does an average overview of a day look like for you?

- Explain care plans and Patient Education.

- What does an admission look like?

- What does giving meds look like?

- What does discharge look like?

Unit shadowed on:

\section{Preceptor name \& signature:}

Time on the unit:

Date:

Feedback from the experience:

\section{Figure 1}

\section{Results}

Patient throughput at our ED is based on the patient's length of stay (LOS) in the ED. LOS is captured from the time of admission in the ED to the patient's arrival to an assigned bed in the receiving unit or discharge home. The throughput time for our holding admitted patient was compared to patients being placed in any other unit in the hospital from the ED. The LOS of patients transferred to the holding unit was noticeably shorter because the ED holding nurses transferred patients who met appropriate criteria promptly to the holding unit. The average LOS for patients on the holding unit was 5 hours and 53 minutes before getting an inpatient bed in addition to the average 7.5 hours' time spent in the ED, which made the overall average time approximately 13.5 hours. The ED LOS of stay for admitted patients waiting in the ED on an inpatient bed before the pilot could be as high as 17 hours. The inpatient unit that received most of our patients from the holding unit was the Medical Progressive unit, followed by the Heart Failure unit (Graph 1). The LWBS rates went from average of $3.4 \%$ to $2.5 \%$. Patients satisfaction scores went from 79.2 to as high as 84.2 . 


\section{Total number of patients transferred to each floor Nov 2018-July 2019}

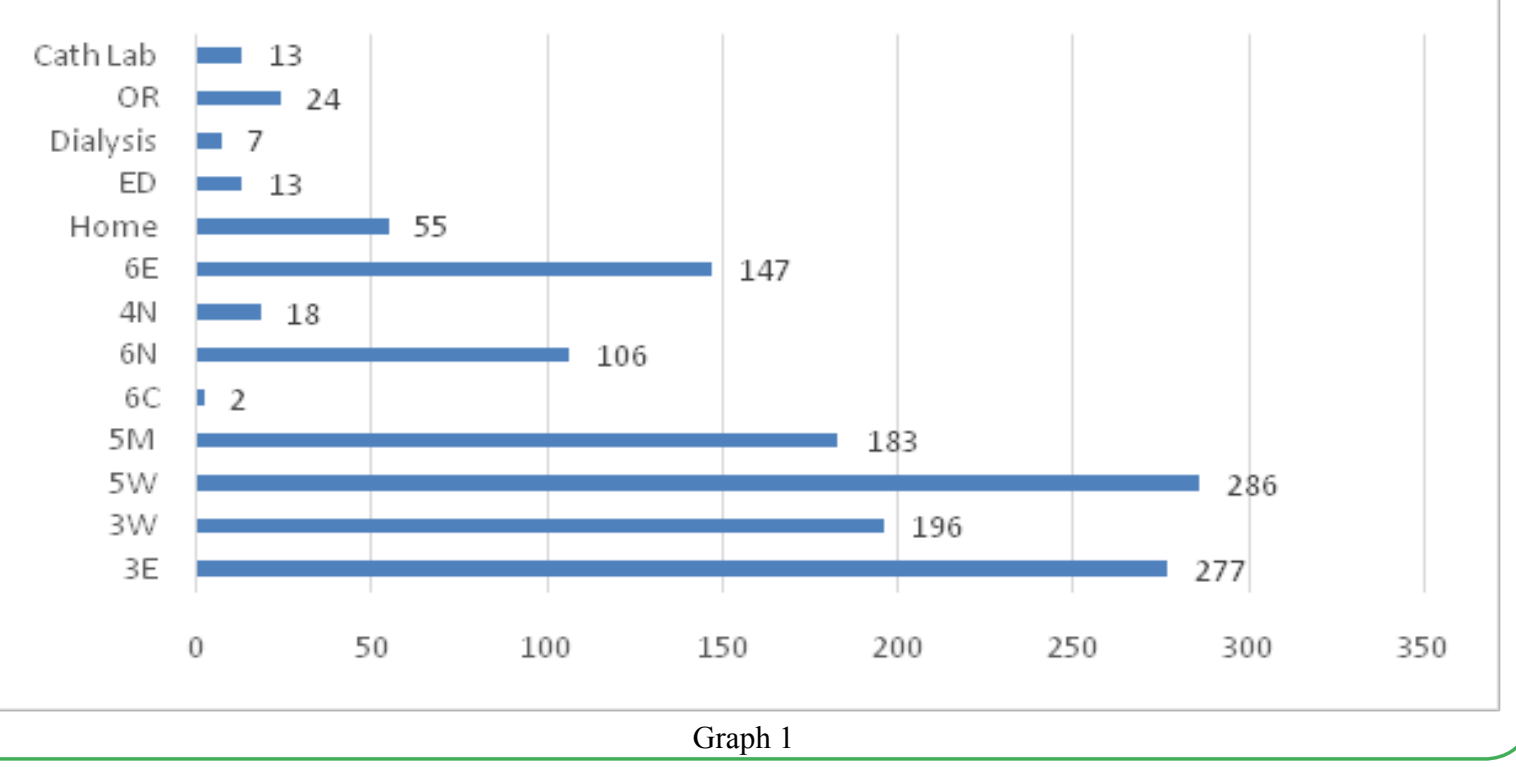

\begin{tabular}{|c|}
\hline APPROPRIATE PATIENTS for 5C \\
\hline Medical Surgical \\
\hline Telemetry \\
\hline Stable Step-downs \\
\hline No Titratable Drips \\
\hline Glucostabilizer Patients (As Long as not lethargic and a 2nd nurse to verify insulin changes) \\
\hline No Active Chest Pain \\
\hline Palliative Care \\
\hline INAPPROPRIATE PATIENTS for 5C \\
\hline Behavioral Health Patients \\
\hline NO Airborne Precautions (No Negative PressureRoom) \\
\hline Patients in 4-point Restraints \\
\hline Pregnant Patients $>\mathbf{2 0}$ Weeks \\
\hline Unstable Stepdowns \\
\hline Hypotension < 90 (Consult Charge about questions of vital stability prior to saying NO) \\
\hline Active Bleeding \\
\hline Active Bipap \\
\hline NSTEMI with Active Chest Pain \\
\hline Titrating Nitro or Vasopressors \\
\hline Lethargic DKA Patient \\
\hline NO ICU PATIENTS \\
\hline
\end{tabular}




\section{Discussion}

The ED staff who worked on this unit shared that this new unit taught them more than they could have ever expected. Many of the staff expressed that by working on this new holding unit they were surprised to find out about so many different subtleties within nursing that they never thought about before. One example of this is how many supplies a unit uses on a regular basis. The day the unit opened, in the process of stocking and ordering supplies, the insulin needles were forgotten. Staff shared that they did not realize that routine nursing care required so many supplies in just one unit and that they could easily miss seemingly insignificant things. This experience has also expanded the ED staff's knowledge of inpatient bedside nursing. The staff shared that having the opportunity to shadow on inpatient medical and telemetry floors enhanced their knowledge of inpatient nursing. By working on this unit, the staffs have become betterrounded by meshing emergency nursing with inpatient nursing. The process of opening this new unit has strengthened the relationship between emergency nurses and the inpatient departments. In addition, another significant impact on the success of this unit was the addition of assigning an ED nurse to round on inpatient units on all shifts to build relationships, address any concerns occurring from patients being received from the holding unit, and identifying the correct scope of care provided on each inpatient unit. The emergency nurses have gained insight into the inpatient care process, which has enhanced the care the patient receives.

\section{Conclusion}

This holding unit has helped the emergency department with the throughput process more than expected. Over the first two months we were able to see over 400 patients on the unit. This equates to about 2,500 total patient care hours. Over the last eight months total number patients cared for on the unit was 1,514 . The total number of patient care hours that were removed from our ED was 11,115 hours. The average time a patient spent on this unit was six hours. If this unit was not open, these patients would have stayed in the $\mathrm{ED}$, unnecessarily occupying rooms that could have been used for patients coming in for emergencies.
The unit has helped with safe patient care by moving the patients out of the emergency setting to an area that is calmer and more focused on inpatient care. The nurses can also focus on their inpatient orders and not be constantly worried about the next trauma or critically ill patient that might come through the doors. The patients are more comfortable within this unit and feel like they are moving on to the next step in the process. Patients have really enjoyed being moved to this unit because they are in rooms with hospital beds that are more comfortable than ED stretchers. The rooms that the patients occupy are more spacious than the ED treatment rooms and have their own individual bathrooms. Due to the rooms being larger, the families of the patients are also more comfortable when visiting their loved ones. This in turn helped with patient satisfaction.

Overall, this unit has increased the productivity of the ED by reducing LWBS rates and the wait time that the patients must endure. This holding unit opening has helped by moving patients to a unit that is more focused and suitable to their needs. Each nurse that works in this new inpatient holding unit has strengthened their skill set and has become a better all-around nurse.

\section{Reference}

1. White BA, Biddinger PD, Chang Y, Grabowski B, Carignan S et al. (2013). Boarding inpatients in the emergency department increases discharged patient length of stay. The J Emergency Med 44: 230-235.

2. Gabele D, Bugais C, Laguna J (2016) Medical observation units and emergency department collaboration: Improving patient throughput. The J Nurs Administration 46: 360-365.

3. Elder E, Johnston AN, Crilly J (2015) Review article: Systematic review of three key strategies designed to improve patient flow through the emergency department. Emergency Medicine Australasia : EMA 27: 394-404.

4. Zocchi MS, McClelland MS, Pines JM (2015) Increasing throughput: Results from a 42-hospital collaborative to improve emergency department flow. Joint Commission J Quality and Patient Safety 41: 532-542. 